\title{
Pengaruh Penerapan Enterprise Resource Planning Terhadap Kinerja Supply Chain Management
}

\author{
Arta Rusidarma Putra ${ }^{1 *}$, Shella Fiolyta ${ }^{1}$ \\ Program Studi Manajemen, Universitas Bina Bangsa \\ JL Raya Serang - Jakarta, KM. 03 No. 1B, Panancangan, Kec. Cipocok Jaya, \\ Kota Serang, Banten, Indonesia 42124 \\ *email : artar.putra@gmail.com
}

\begin{abstract}
Artikel Info ABSTRAK
Received:

7 Juli 2018

Revised:

2 September 2018 Accepted:

15 September 2018

Penelitian ini bertujuan untuk mengetahui pengaruh implementasi Enterprise Resource Planning (ERP) terhadap kinerja Supply Chain Management (SCM) di PT Latinusa Tbk. Sampel yang digunakan dalam penelitian ini adalah sebanyak 100 orang responden dengan menggunakan teknik pengambilan sampel yang berupa random sampling. Instrumen yang dipergunakan untuk mengumpulkan data adalah daftar kuesioner berupa skala model Likert dan disusun berdasarkan konstruksi dari berbagai teori. Model analisis yang digunakan dalam penelitian ini adalah Analisis Deskriptif, Analisis Structural Equation Model (SEM) dengan program AMOS. Hasil penelitian menunjukan bahwa implementasi ERP yang terdiri dari manfaat operasional, taktis, dan strategis berpengaruh signifikan terhadap kinerja SCM yang terdiri dari bisnis internal, bisnis eksternal, layanan pelanggan, dan dalam manajemen biaya PT. Latinusa Tbk. Hal ini dapat diartikan, jika implementasi ERP mengalami peningkatan, maka kinerja SCM juga akan mengalami peningkatan.
\end{abstract}

Kata kunci: Enterprise Resource Planning , Supply Chain Management

\section{Effect of Application of Enterprise Resource Planning to Supply Chain Management Performance}

\begin{abstract}
This study aims to determine the effect of implementing Enterprise Resource Planning (ERP) on the performance of Supply Chain Management (SCM) at PT Latinusa Tbk. The sample used in this study was 100 respondents using a sampling technique in the form of random sampling. The instrument used to collect data is a list of questionnaires in the form of Likert model scale and arranged based on the constructs of various theories. The analytical model used in this study is Descriptive Analysis, Analysis of Structural Equation Model (SEM) with AMOS programs. The results showed that ERP implementation consisting of operational, tactical and strategic benefits had a significant effect on SCM's performance consisting of internal business, external business, customer service, and in cost management of PT. Latinusa Tbk. This can be interpreted, if the ERP implementation has increased, the performance of SCM will also increase.
\end{abstract}

Keywords: Enterprise Resource Planning, Supply Chain Management

Cara Sitasi :

Putra, A. R., Fiolyta, S. (2018). Pengaruh Penerapan Enterprise Resource Planning Terhadap Kinerja Supply Chain Management. Jurnal Ilmiah Manajemen dan Bisnis, 19(2), 97-109. https://doi.org/ 10.30596/jmanbis.v19i2.2090 


\section{PENDAHULUAN}

Era globalisasi masa kini arus informasi sangatlah cepat. Perkembangan ilmu pengetahuan dan teknologi sangat berpengaruh terhadap kemajuan perusahaan. Metode bisnis elektronik memungkinkan perusahaan untuk menghubungkan seluruh informasi dan aktivitas internal dan eksternal perusahaan sehingga sistem pengolahan data lebih efisien dan fleksibel, bekerja lebih sistematis dan terintegrasi dengan pemasok dan distributor, serta lebih memenuhi kebutuhan dan harapan pelanggan. Sistem informasi dituntut dapat mendukung perubahan kondisi bisnis dengan cepat. Peningkatan kinerja perusahaan salah satunya dengan penerapan teknologi informasi dalam aktivitas perusahaan yang dapat meningkatkan keunggulan dan daya saing. Dalam rangka mewujudkan kehandalan informasi, perusahaan dapat menerapkan suatu sistem informasi yang dapat mengintegrasikan semua aktivitas dan fungsi yang ada di dalam perusahaan (Kurniawati et al., 2011).

$$
\text { Menurut Tarigan, }
$$

Implementasi sistem informasi yang ada dalam organisasi bisnis dimulai dari yang paling sederhana sampai yang paling kompleks, yang berbasis enterprise. Implementasi sistem informasi yang berbasis enterprise ini seringkali disebut sebagai Enterprise Resource Planning (ERP) yang menjadi salah satu sistem informasi yang digunakan untuk meningkatkan kinerja perusahaan dengan penerapan teknologi. ERP adalah suatu software yang ditujukan untuk enterprise dalam membantu organisasi untuk mengelola dan membuat efektif penggunaan sumber daya (materials, human resources, finance, dan sebagainya) dengan menyediakan solusi terintegrasi untuk mengolah informasi yang dibutuhkan (Saini et al., 2013).
ERP dianggap sebagai bahan penting yang dibutuhkan perusahaan untuk bisa mendapatkan efisensi, kelincahan, dan responsivitas yang dibutuhkan dalam mencapai keberhasilan dalam lingkungan bisnis yang dinamis saat ini. Dengan bantuan ERP juga perusahaan di Indonesia dapat terintegrasi pada setiap proses dalam perusahaan tersebut ke dalam suatu sistem komputerisasi.

Penggunaan sistem ERP juga dapat mengurangi waktu dan total biaya operasi karena ERP menyediakan informasi yang dibutuhkan untuk memfasilitasi pengambilan keputusan dan aktivitas organisasi Abu-Shanab et al., (2015). Implementasi ERP yang sukses akan mengakibatkan dampak penting dan manfaat bagi organisasi. Implikasi ini dapat dievaluasi berdasarkan sudut pandang yang berbeda. Salah satu perspektif menunjukkan manfaat sistem ERP pada organisasi dan efeknya terhadap area lain atau sistem TI lain seperti sistem Supply Chain Management (SCM) yang terintegrasi dengannya (Tarhini et al., 2015).

Model pengukuran yang menganggap kinerja supply chain mewakili lima bidang utama kinerja yaitu layanan pelanggan, manajemen biaya, kualitas, produktivitas, dan manajemen aset (Bowersox et al., 2002). Sedangkan kerangka kerja untuk mengukur kinerja supply chain yang terdiri dari tiga tingkatan: strategis, taktis, dan operasional. Kerangka ini terdiri dari empat perspektif: perspektif keuangan, perspektif pelanggan, perspektif proses bisnis, dan perspektif pembelajaran dan pertumbuhan (Gunasekaran et al., 2009)

Penelitian ini tertuju pada pengaruh pemakaian sistem ERP terhadap kinerja $S C M$ secara terbatas dan tidak meyakinkan. Oleh karena itu, penelitian saat ini membahas kesenjangan dengan menguji pengaruh penerapan sistem ERP (enterprise Resource Planning) terhadap kinerja SCM 
(Supply Chain Management). Bukti bahwa industri kaleng kemasan PT Latinusa Tbk., yang telah berhasil menjalankan SAP ERP sejak 11 Januari 2013 dan telah berhasil menuju visi perusahaan untuk menjadi perusahaan kemasan baja terdepan di kawasan AFTA (ASEAN Free Trade Area).

Penelitian yang dilakukan oleh Akkermans et al., (2003) mempelajari dampak penerapan sistem ERP pada manajemen rantai pasokan di waktu yang akan datang. Salah satu temuan utamanya adalah peran sederhana pada ERP dalam meningkatkan efektifitas rantai pasokan di waktu yang akan datang dan resiko penerapan sistem ERP yang sebenarnya membatasi kemajuan dalam SCM. Selain itu, mereka mengidentifikasi keterbatasan utama dari sistem ERP dalam memberikan dukungan $S C M$ yang efektif.

Forslund, (2010) mengatakan bahwa adanya kemampuan sistem ERP dalam membantu dan mengevaluasi pengelolaan kinerja supply chain. Melalui studi empiris, berdasarkan kerangka dengan mewawancarai responden selama 12 tahun di pasar Swedia akhirnya menyimpulkan bahwa perlu adanya pengembangan kerangka kerja untuk permintaan pengadaan dari rantai pasokan supply chain. Adapun sistem yang mendukung kemampuan rantai pasokan yang baik untuk pengelolaan kinerja supply chain adalah Oracle. Dengan meningkatnya kinerja hal ini akan meningkatkan pendapatan dan menjadi acuan bagi perusahaan untuk meningkatkan nilai perusahaan. Penelitian tersebut kembali dibuktikan oleh Wicaksono et,al., (2015), dalam penelitiannya yang menyatakan bahwa penerapan sistem ERP memiliki dampak positif terhadap komponen kinerja pengguna.

Perusahaan yang paling banyak menerapkan ERP adalah perusahaan yang bergerak di bidang manufaktur. Penelitian ini juga pernah diteliti di India oleh beberapa peneliti antara lain. Banwait et al., (2010) dalam penelitiannya peneliti menemukan bahwa tingkat penjualan mampu memoderasi pengaruh penerapan ERP terhadap kinerja perusahaan. Shang et al., (2000) memberikan suatu kerangka komprehensif dari manfaat sistem ERP. Mereka menemukan bahwa semua organisasi mendapatkan manfaat klasifikasi dari lima kategori: infrastruktrur IT, operasional, manajerial, strategis dan manfaat organisasional. Penelitian ini juga telah mencakup dan mendasar pada dua area yaitu klasifikasi manfaat ERP.

Sedangkan penelitian yang dilakukan oleh Bowesox et al., (1999) menghasilkan hipotesis bahwa manfaat ERP mencakup tiga dimensi yaitu manfaat operasional, manfaat taktis, dan manfaat strategis. Sedangkan pada kinerja SCM terdapat empat dimensi yaitu bisnis proses internal, bisnis proses eksternal, layanan konsumen, dan manajemen biaya. Ketujuh dimensi tersebut adalah hal yang dirasakan langsung oleh para manajer, pelanggan, pemasok, distributor, dan perusahaan lain dan semua dimensi tersebut penting dalam membangun kinerja perusahaan yang efektif.

Penelitian ini, penulis membangun model penelitian berdasarkan pada studi literatur tentang Enterprises Resource Planning, Supply Chain Management, dan pengukuran kinerja Supply Chain Management. Seperti telah dibahas sebelumnya, beberapa peneliti telah memberikan kontribusi pada penggunaan sistem ERP yang berhubungan dengan rantai pasokan, namun tujuan penelitian ini adalah untuk menguji secara rinci pengaruh penerapan ERP terhadap kinerja SCM. Dengan demikian, model penelitian ini bergantung pada dua bidang: manfaat ERP sebagaimana dimaksud berdasarkan kinerja SCM (Bowesox et al.,1999) Berikut model penelitian dan hipotesis yang dibangun pada penelitian ini: 


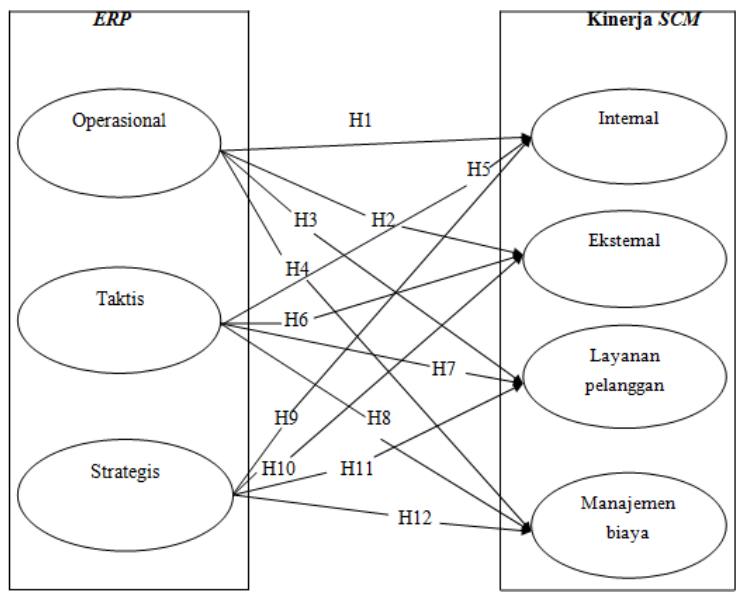

Gambar 1. Model Penelitian

H1 : Manfaat operasional ERP berpengaruh terhadap kinerja SCM di proses bisnis internal

$\mathrm{H} 2$ : Manfaat operasional ERP berpengaruh terhadap kinerja SCM diproses bisnis eksternal

H3 : Manfaat operasional ERP berpengaruh terhadap kinerja SCM pada layanan pelanggan

H4 : Manfaat operasional ERP berpengaruh terhadap kinerja SCM dalam biaya manajemen biaya.

H5 : Manfaat taktis ERP berpengaruh terhadap kinerja SCM diproses bisnis internal

H6 : Manfaat taktis ERP berpengaruh terhadap kinerja SCM diproses bisnis eksternal

H7 : Manfaat taktis ERP berpengaruh terhadap kinerja SCM pada layanan pelanggan

H8 : Manfaat taktis ERP berpengaruh terhadap kinerja SCM dalam manajemen biaya

H9 : Manfaat strategis ERP berpengaruh terhadap kinerja SCM di proses bisnis internal

H10 : Manfaat strategis ERP berpengaruh terhadap kinerja SCM di proses bisnis eksternal
H11 : Manfaat strategis ERP berpengaruh terhadap kinerja SCM dilayanan pelanggan

H12 : Manfaat strategis ERP berpengaruh terhadap kinerja SCM dalam manajemen biaya

\section{METODE}

Fokus kajian ini meliputi pembahasan mengenai pengaruh penerapan sistem ERP terhadap kinerja SCM, dengan demikian ruang lingkup penelitian ini menyangkut dua variabel yaitu variabel penerapan sistem ERP dan variabel kinerja SCM. Jenis data yang digunakan dalam penelitian ini adalah data primer. Sumber data primer tersebut diperoleh dari PT Latinusa melalui angket/kuisioner yang diberikan kepada karyawan. Untuk keperluan pengujian hipotesis yang akan dilakukan di dalam penelitian ini diperlukan sejumlah data sampel dengan menggunakan metode Slovin $n=\mathrm{N} /\left(1+\mathrm{N} \mathrm{e}^{2}\right)=134 /\left(1+134 \times 0,05^{2}\right)$ $=100,37=100$. Sedangkan teknik sampling yang digunakan untuk mendapatkan jumlah sampel yang dibutuhkan berupa random sampling yang mampu menjelaskan karakteristik populasi dengan seimbang. Uji kualitas instrumen menggunakan uji validitas dan uji reliabilitas. Uji Validitas adalah suatu kuesioner dikatakan valid jika pertanyaan pada kuesioner mampu untuk mengungkapkan sesuatu yang akan diukur oleh kuesioner tersebut. Cronbach's Alpha > dari 0,60. Alat analisis data yang digunakan untuk membahas permasalahan dalam penelitian ini adalah Structural Equation Model (SEM) yang dioperasikan melalui program AMOS. Alasan memakai SEM karena model yang dianalisis bertingkat dan relatif rumit, sehingga akan sangat sulit untuk diselesaikan dengan metode jalur analisis pada regresi linear dan dapat menyelesaikan model persamaan dengan variabel terikat lebih dari satu dan juga pengaruh timbal balik (recursive). 


\section{HASIL DAN PEMBAHASAN}

Berdasarkan hipotesis manfaat ERP dan kinerja SCM, penelitian ini mencoba membuktikan adanya pengaruh manfaat operasional (X1), manfaat taktis (X2) dan strategis (X3) terhadap proses bisnis internal (Y1), proses bisnis eksternal (Y2), layanan konsumen (Y3) dan manajemen biaya (Y4) yang kemudian dibangun butir pertanyaan dalam kuisioner sebagai berikut :

Tabel 1. Indikator Variabel

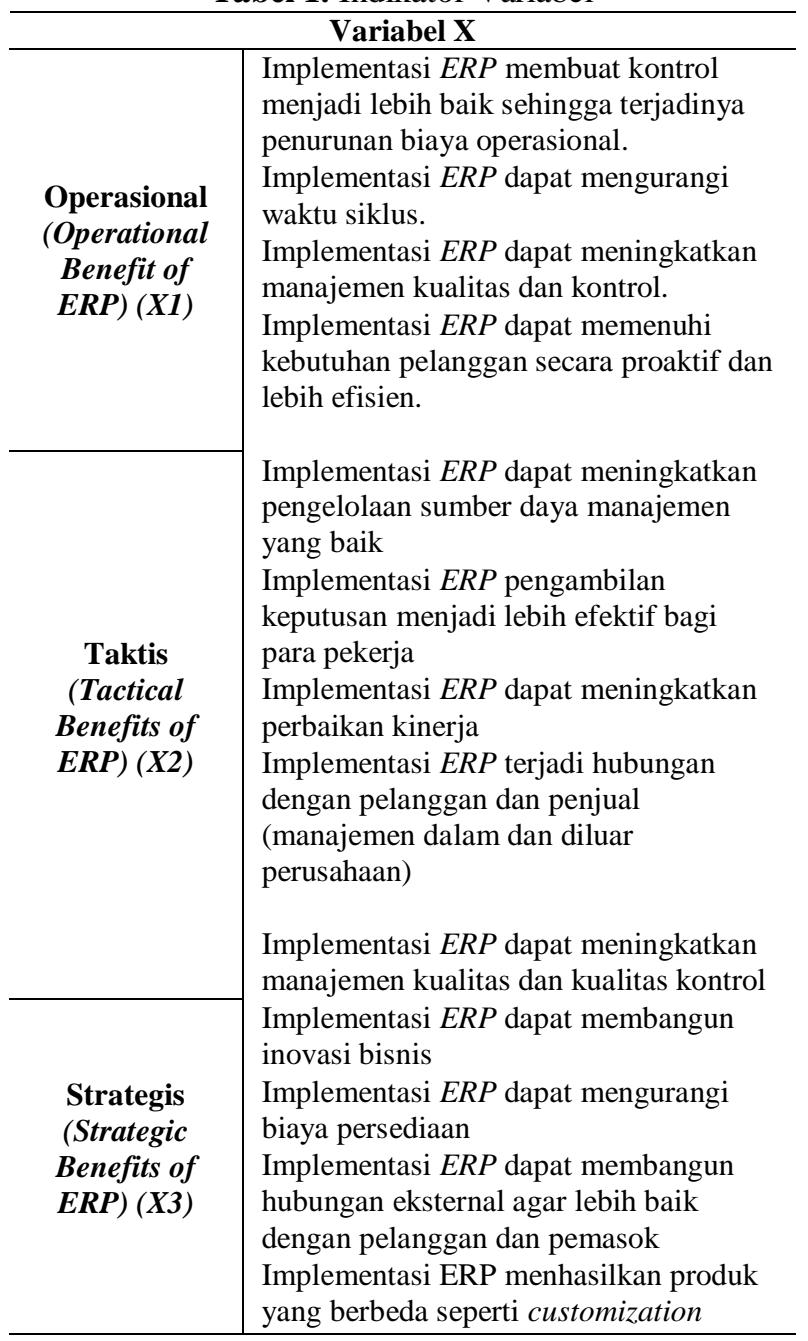

\begin{tabular}{cl}
\hline & \multicolumn{2}{c}{ Variabel Y } \\
\hline Internal & Implementasi ERP proses manufaktur \\
(Internal & menjadi efisien sehingga dapat \\
Business & meningkatkan manajemen persediaan \\
Process & Implementasi ERP dapat meningkatkan \\
Perspective) & kontrol dengan lebih baik \\
$($ Y1) & Implementasi ERP pengiriman menjadi
\end{tabular}

efisien

Implementasi $E R P$ dapat meningkatkan fleksibilitas

Implementasi ERP mampu meningkatkan produk baru ke pasar Implementasi $E R P$ dapat mendukung informasi yang lebih baik dan penjadwalan yang lebih baik

Implementasi ERP pengiriman menjadi tepat waktu ke pemasok Implementasi ERP meningkatkan kerjasama dengan mitra lain

(External

Business

Process

Perspective) (Y2) Implementasi $E R P$ pengiriman menjadi fleksibilitas

Implementasi ERP meningkatkan transaksi order pembelian secara efisien Implementasi ERP mampu berbagi informasi persediaan Implementasi $E R P$ dapat meningkatkan hubungan dengan pelanggan

Layanan Implementasi ERP meningkatkan

Pelanggan

(Customer Service

Perspective)

(Y3)

kualitas produk dan peningktan pelanggan dalam pengembalian produk Implementasi ERP membuat produk menjadi fleksibilitas

Implementasi ERP mampu untuk pelacakan informasi kinerja Implementasi $E R P$ dapat memesan produk secara tepat waktu

Manajemen Implementasi $E R P$ laba perusahaan menjadi meningkat

Biaya (Cost

Management

Perspective)

(Y4) Implementasi ERP meningkatkan total pendapatan pertumbuhan penjualan Implementasi ERP struktur biaya perusahaan menjadi lebih baik

Berdasarkan hasil penelitian untuk uji validitas, nilai ryx $\mathrm{X} 1$ pertanyaan butir 1 sebesar $0,578, \mathrm{X} 1$ pertanyaan butir 2 sebesar $0,548, X 1$ pertanyaan butir 3 sebesar 0,584 dan X1 pertanyaan butir 4 sebesar 0,539. Karena keseluruhan nilai rxy $>0,195$, maka seluruh item-item pertanyaan pada seluruh variabel dinyatakan valid. Sedangkan dalam uji reliabilitas, didapat nilai Cronbach Alpha X1 sebesar 0,760, karena nilai Cronbach's Alpha > 0,60 sehingga seluruh variabel dinyatakan reliabel dan dapat dipakai untuk uji selanjutnya. Berdasarkan hasil penelitian untuk uji validitas, nilai ryx X2 pertanyaan butir 1 sebesar $0,525, \mathrm{X} 2$ pertanyaan butir 2 sebesar $0,721, \mathrm{X} 2$ pertanyaan butir 3 sebesar 
0,599 dan X2 pertanyaan butir 4 sebesar 0,660. Karena keseluruhan nilai rxy > 0,195, maka seluruh item-item pertanyaan pada seluruh variabel dinyatakan valid. Sedangkan dalam uji reliabilitas, didapat nilai Cronbach Alpha X2 sebesar 0,823, karena nilai Cronbach's Alpha $>0,60$ sehingga seluruh variabel dinyatakan reliabel dan dapat dipakai untuk uji selanjutnya. Berdasarkan hasil penelitian untuk uji validitas, nilai ryx $\mathrm{X} 3$ pertanyaan butir 1 sebesar $0,743, \mathrm{X} 3$ pertanyaan butir 2 sebesar $0,709, \mathrm{X} 3$ pertanyaan butir 3 sebesar 0,743 dan X3 pertanyaan butir 4 sebesar 0,698. Karena keseluruhan nilai rxy $>0,195$, maka seluruh item-item pertanyaan pada seluruh variabel dinyatakan valid. Sedangkan dalam uji reliabilitas, didapat nilai Cronbach Alpha X3 sebesar 0,874, karena nilai Cronbach's Alpha $>0,60$ sehingga seluruh variabel dinyatakan reliabel dan dapat dipakai untuk uji selanjutnya. Berdasarkan hasil penelitian untuk uji validitas, nilai ryx Y1 pertanyaan butir 1 sebesar $0,575, \mathrm{Y} 1$ pertanyaan butir 2 sebesar 0,492, Y1 pertanyaan butir 3 sebesar 0,626 , Y1 pertanyaan butir 4 sebesar 0,638 , Y1 pertanyaan butir 5 sebesar 0,537 dan Y1 pertanyaan butir 6 sebesar 0,511. Karena keseluruhan nilai rxy $>0,195$, maka seluruh item-item pertanyaan pada seluruh variabel dinyatakan valid. Sedangkan dalam uji reliabilitas, didapat nilai Cronbach Alpha Y1 sebesar 0,884, karena nilai Cronbach's Alpha > 0,60 sehingga seluruh variabel dinyatakan reliabel dan dapat dipakai untuk uji selanjutnya. Berdasarkan hasil penelitian untuk uji validitas, nilai ryx Y2 pertanyaan butir 1 sebesar $0,627, \mathrm{Y} 2$ pertanyaan butir 2 sebesar 0,618 , Y2 pertanyaan butir 3 sebesar $0,692, \mathrm{Y} 2$ pertanyaan butir 4 sebesar 0,610 , dan Y2 pertanyaan butir 5 sebesar 0,670. Karena keseluruhan nilai rxy > 0,195, maka seluruh item-item pertanyaan pada seluruh variabel dinyatakan valid. Sedangkan dalam uji reliabilitas, didapat nilai Cronbach Alpha
Y2 sebesar 0,884, karena nilai Cronbach's Alpha > 0,60 sehingga seluruh variabel dinyatakan reliabel dan dapat dipakai untuk uji selanjutnya. Berdasarkan hasil penelitian untuk uji validitas, nilai ryx Y3 pertanyaan butir 1 sebesar $0,595, \mathrm{Y} 3$ pertanyaan butir 2 sebesar 0,662, Y3 pertanyaan butir 3 sebesar 0,669 , Y3 pertanyaan butir 4 sebesar 0,711 , dan Y3 pertanyaan butir 5 sebesar 0,547. Karena keseluruhan nilai rxy $>0,195$, maka seluruh item-item pertanyaan pada seluruh variabel dinyatakan valid. Sedangkan dalam uji reliabilitas, didapat nilai Cronbach Alpha Y3 sebesar 0,834, karena nilai Cronbach's Alpha > 0,60 sehingga seluruh variabel dinyatakan reliabel dan dapat dipakai untuk uji selanjutnya. Berdasarkan hasil penelitian untuk uji validitas, nilai ryx Y4 pertanyaan butir 1 sebesar $0,697, \mathrm{Y} 4$ pertanyaan butir 2 sebesar 0,677, Y4 pertanyaan butir 3 sebesar 0,599,. Karena keseluruhan nilai rxy > 0,195 , maka seluruh item-item pertanyaan pada seluruh variabel dinyatakan valid. Sedangkan dalam uji reliabilitas, didapat nilai Cronbach Alpha Y4 sebesar 0,808, karena nilai Cronbach's Alpha > 0,60 sehingga seluruh variabel dinyatakan reliabel dan dapat dipakai untuk uji selanjutnya.

Selanjutnya dilakukan Analisis signifikansi bobot faktor pada dasarnya adalah untuk menguji unidimensionalitas dari indikator-indikator yang menjelaskan sebuah faktor atau sebuah variabel laten. Untuk tujuan tersebut setiap indikator dalam penelitian ini diuji apakah secara bersamasama cukup kuat mencerminkan sebuah dimensi dari suatu faktor. Evaluasi yang dipakai untuk tujuan tersebut adalah melihat nilai $t$ hitung dari parameter dan nilai signifikansinya. Holmes-Smith, (2001) menyatakan bahwa pada $\alpha=0,05$ parameter yang memiliki nilai $t>1,96$ menunjukkan parameter tersebut signifikan atau valid. Disamping itu nilai signifikansi dibawah 0,05 juga menunjukkan parameter tersebut 


\section{JURNAL ILMIAH MANAJEMEN DAN BISNIS ISSN 1693-7619 (print) | ISSN 2580-4170 (online), http://jurnal.umsu.ac.id/index.php/mbisnis}

signifikan merupakan unidimensionalitas dari suatu faktor yang diuji.

Tabel 2. Hasil Uji Signifikansi Bobot Faktor

\begin{tabular}{|c|c|c|c|c|}
\hline Variabel & Item & t-value & p-value & Keterangan \\
\hline \multirow{5}{*}{ Operasional } & EO1 & 1 & - & \\
\hline & $\mathrm{EO} 2$ & 5.454 & 0,000 & Diterima \\
\hline & EO3 & 5.364 & 0,000 & Diterima \\
\hline & EO4 & 4.824 & 0,000 & Diterima \\
\hline & ET5 & 1 & - & \\
\hline \multirow{3}{*}{ Taktis } & ET4 & 6.439 & 0,000 & Diterima \\
\hline & ET3 & 5.753 & 0,000 & Diterima \\
\hline & ET2 & 6.720 & 0,000 & Diterima \\
\hline \multirow{6}{*}{ Strategis } & ET1 & 5.364 & 0,000 & Diterima \\
\hline & ES4 & 1 & - & \\
\hline & ES3 & 8.409 & 0,000 & Diterima \\
\hline & ES2 & 7.843 & 0,000 & Diterima \\
\hline & ES1 & 7.822 & 0,000 & Diterima \\
\hline & SIBP1 & 1 & - & \\
\hline \multirow{4}{*}{ Internal } & SIBP2 & 5.624 & 0,000 & Diterima \\
\hline & SIBP3 & 7.434 & 0,000 & Diterima \\
\hline & SIBP4 & 5.971 & 0,000 & Diterima \\
\hline & SIBP5 & 6.093 & 0,000 & Diterima \\
\hline \multirow{3}{*}{ Eksternal } & SIBP6 & 5.113 & 0,000 & Diterima \\
\hline & SEBP1 & 1 & - & \\
\hline & SEBP2 & 6.956 & 0,000 & Diterima \\
\hline \multirow{7}{*}{$\begin{array}{l}\text { Layanan } \\
\text { Pelanggan }\end{array}$} & SEBP3 & 8.009 & 0,000 & Diterima \\
\hline & SEBP4 & 7.097 & 0,000 & Diterima \\
\hline & SEBP5 & 7.511 & 0,000 & Diterima \\
\hline & & & - & \\
\hline & SCS1 & 1 & & \\
\hline & SCS2 & 6.444 & 0,000 & Diterima \\
\hline & SCS3 & 5.918 & 0,000 & Diterima \\
\hline \multirow{5}{*}{$\begin{array}{c}\text { Manajemen } \\
\text { Biaya }\end{array}$} & SCS4 & 6.296 & 0,000 & Diterima \\
\hline & SCS5 & 5.009 & 0,000 & Diterima \\
\hline & SCM1 & 1 & - & \\
\hline & $\mathrm{SCM} 2$ & 7.414 & 0,000 & Diterima \\
\hline & SCM3 & 6.775 & 0,000 & Diterima \\
\hline
\end{tabular}

Analisis model persamaan struktural secara penuh (full structural equation model analysis) dapat dilihat pada Gambar 1 berikut:

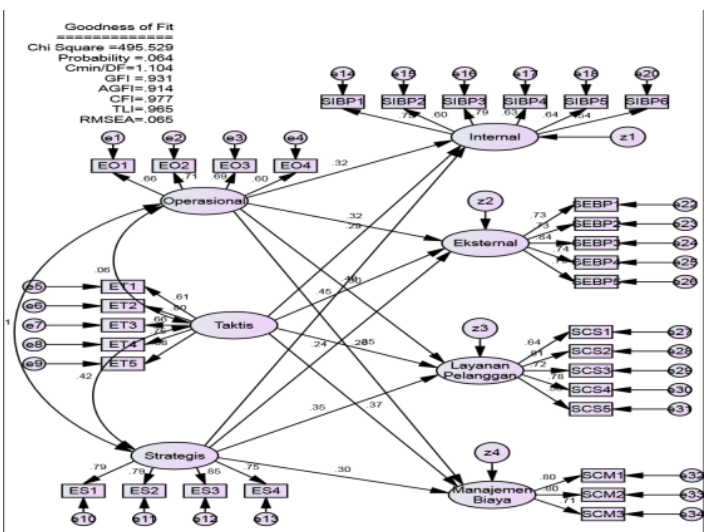

Gambar 2. Full Model Struktural
Berikut ini ringkasan perbandingan model yang dibangun dengan cut-off goodness-of fit indices yang ditetapkan.

Tabel 3. Hasil Goodness of Fit Index

\begin{tabular}{cccc}
\hline $\begin{array}{c}\text { Goodness of } \\
\text { Fit }\end{array}$ & Nilai & Cut-off Value & Keterangan \\
\hline Chi-Square & 495,529 & Diharapkan & Baik \\
$\left(\chi^{2}\right)$ & $(0,064)$ & kecil & Baik \\
RMSEA & 0,065 & $\leq 0,08$ & Baik \\
GFI & 0,931 & $\geq 0,90$ & Baik \\
CMN/DF & 1,104 & $\leq 2,00$ & Baik \\
TLI & 0,965 & $\geq 0,95$ & Baik \\
CFI & 0,977 & $\geq 0,95$ & Baik \\
\hline
\end{tabular}

Berdasarkan hasil uji kesesuaian model bahwa nilai RMSEA < nilai kritisnya $=0,080$, GFI > 0,90, dan TLI dan CFI $\geq$ 0,90 . Hal ini berarti model persamaan structural dalam penelitian ini adalah fit (memiliki kesesuaian). Berikut ini adalah output tabel pengujian hipotesis penelitian dengan menggunakan alat uji AMOS dalam bentuk output Regression Weights seperti pada tabel 4 berikut:

Tabel 4. output Regression Weights

\begin{tabular}{|c|c|c|c|}
\hline Jalur & Estimate & $\begin{array}{l}\text { C. } \\
\text { R. }\end{array}$ & Prob. \\
\hline Operasional (ERP) $\rightarrow$ & \multirow{2}{*}{0,309} & 2,7 & \multirow{2}{*}{0,006} \\
\hline Internal (SCM) & & 56 & \\
\hline Operasional (ERP) $\rightarrow$ & \multirow{2}{*}{0,344} & 2,7 & \multirow{2}{*}{0,006} \\
\hline Eksternal (SCM) & & 66 & \\
\hline Operasional (ERP) $\rightarrow$ & \multirow{2}{*}{0,232} & 2,4 & \multirow{2}{*}{0,013} \\
\hline Layanan Pelanggan (SCM) & & 73 & \\
\hline Operasional $(\mathrm{ERP}) \rightarrow$ & \multirow{2}{*}{0,272} & 2,0 & \multirow{2}{*}{0,038} \\
\hline Manajemen Biaya (SCM) & & 72 & \\
\hline $\begin{array}{l}\text { Taktis }(\text { ERP) } \rightarrow \text { Internal } \\
(\mathrm{SCM})\end{array}$ & 0,460 & $\begin{array}{l}3,5 \\
81\end{array}$ & 0,000 \\
\hline Taktis $($ ERP) $\rightarrow$ Eksternal & \multirow{2}{*}{0,264} & 2,0 & \multirow{2}{*}{0,045} \\
\hline$(\mathrm{SCM})$ & & 07 & \\
\hline Taktis (ERP) $\rightarrow$ Layanan & \multirow{2}{*}{0,282} & 2,6 & \multirow{2}{*}{0,007} \\
\hline Pelanggan (SCM) & & 94 & \\
\hline Taktis (ERP) $\rightarrow$ Manajemen & \multirow{2}{*}{0,331} & 2,2 & \multirow{2}{*}{0,024} \\
\hline Biaya (SCM) & & 50 & \\
\hline Strategis $(\mathrm{ERP}) \rightarrow$ Internal & \multirow{2}{*}{0,343} & 2,6 & \multirow{2}{*}{0,007} \\
\hline (SCM) & & 88 & \\
\hline Strategis (ERP) $\rightarrow$ Eksternal & \multirow[t]{2}{*}{0,616} & $\begin{array}{l}3,8 \\
82\end{array}$ & \multirow[t]{2}{*}{0,000} \\
\hline$(\mathrm{SCM})$ & & 82 & \\
\hline Strategis $(\mathrm{ERP}) \rightarrow$ Layanan & \multirow[t]{2}{*}{0,323} & 2,8 & \multirow[t]{2}{*}{0,004} \\
\hline $\begin{array}{l}\text { Pelanggan }(\mathrm{SCM}) \\
\text { Strategis }(\mathrm{ERP}) \rightarrow\end{array}$ & & $\begin{array}{r}83 \\
29\end{array}$ & \\
\hline Manajemen Biaya (SCM) & 0,469 & $\begin{array}{l}2,9 \\
55\end{array}$ & 0,003 \\
\hline
\end{tabular}

Tabel, dapat kita lihat bahwa seluruh hipotesis yang diajukan terdukung pada tingkat signifikansi 0,05. Hasil analisis Structural Equation Model (SEM) 
menunjukan bahwa variabel manfaat operasional ERP $\left(\mathrm{X}_{1}\right)$ terhadap variabel Kinerja $S C M$ di proses bisnis internal $\left(\mathrm{Y}_{1}\right)$, kinerja SCM di proses bisnis eksternal $\left(\mathrm{Y}_{2}\right)$, kinerja $S C M$ pada layanan pelanggan $\left(\mathrm{Y}_{3}\right)$ dan kinerja $S C M$ dalam manajemen biaya $\left(\mathrm{Y}_{4}\right)$ PT Latinusa Tbk. Dengan taraf nyata $($ probabilitas $)=5 \%=0,05$. Hal ini dapat diartikan, jika manfaat operasional ERP menurut responden dapat mengurangi waktu siklus, meningkatkan manajemen kualitas dan kontrol, dan dapat memenuhi kebutuhan pelanggan secara proaktif dan lebih efisien.

Kemudian pada variabel manfaat taktis ERP $\left(\mathrm{X}_{2}\right)$ terhadap variabel Kinerja $S C M$ di proses bisnis internal $\left(\mathrm{Y}_{1}\right)$, kinerja SCM di proses bisnis eksternal $\left(\mathrm{Y}_{2}\right)$, kinerja $S C M$ pada layanan pelanggan $\left(\mathrm{Y}_{3}\right)$ dan kinerja $S C M$ dalam manajemen biaya $\left(\mathrm{Y}_{4}\right)$ PT Latinusa Tbk. Dengan taraf nyata (probabilitas) $=5 \%=0,05$. Hal ini dapat diartikan, jika manfaat taktis ERP menurut responden dapat meningkatkan pengelolaan sumber daya manajemen yang baik, pengambilan keputusan menjadi lebih efektif bagi para pekerja, meningkatkan perbaikan kinerja, terjadi hubungan dengan pelanggan dan penjual (manajemen dalam dan diluar perusahaan), dan dapat meningkatkan manajemen kualitas dan kualitas kontrol.

Sedangkan pada variabel manfaat strategis $\operatorname{ERP}\left(\mathrm{X}_{3}\right)$ terhadap variabel Kinerja $S C M$ di proses bisnis internal $\left(\mathrm{Y}_{1}\right)$, kinerja SCM di proses bisnis eksternal $\left(\mathrm{Y}_{2}\right)$, kinerja $S C M$ pada layanan pelanggan $\left(\mathrm{Y}_{3}\right)$ dan kinerja $S C M$ dalam manajemen biaya $\left(\mathrm{Y}_{4}\right)$ PT Latinusa Tbk. Dengan taraf nyata (probabilitas) $=5 \%=0,05$. Artinya hal ini manfaat strategis dapat membangun inovasi bisnis, implementasi ERP dapat mengurangi biaya persediaan, implementasi ERP dapat membangun hubungan eksternal agar lebih baik dengan pelanggan dan pemasok, dan implementasi ERP menhasilkan produk yang berbeda seperti customization .

\section{Pembahasan}

Hasil analisis Structural Equation Model (SEM) menunjukkan bahwa pengujian pengaruh variabel manfaat operasional ERP $\left(\mathrm{X}_{1}\right)$ terhadap variabel Kinerja $S C M$ di proses bisnis internal PT. Latinusa Tbk $\left(\mathrm{Y}_{1}\right)$. Dengan taraf nyata (probabilitas) $=5 \%=0,05$ dan dari hasil Regresi SEM diperoleh probabilitas $\mathrm{t}_{\text {-hitung }}=$ 0,006. Berdasarkan hasil olah data diperoleh nilai probabilitas $t_{\text {-hitung }}(0,006)<$ Level of Significant $(0,05)$, maka disimpulkan bahwa variabel manfaat operasional ERP $\left(\mathrm{X}_{1}\right)$ berpengaruh signifikan terhadap Kinerja $S C M$ di proses bisnis internal PT. Latinusa Tbk $\left(\mathrm{Y}_{1}\right)$. Hal ini dapat diartikan, jika manfaat operasional ERP meningkat dalam arti bahwa, jika menurut responden implementasi ERP dapat mengurangi waktu siklus, implementasi ERP dapat meningkatkan manajemen kualitas dan kontrol, dan implementasi ERP dapat memenuhi kebutuhan pelanggan secara proaktif dan lebih efisien, maka Kinerja $S C M$ di proses bisnis internal PT. Latinusa Tbk akan mengalami peningkatan.

\section{Hasil analisis Structural Equation} Model (SEM) menunjukkan bahwa Pengujian pengaruh variabel manfaat operasional ERP $\left(\mathrm{X}_{1}\right)$ terhadap variabel Kinerja $S C M$ di proses bisnis eksternal PT. Latinusa Tbk $\left(\mathrm{Y}_{2}\right)$. Dengan taraf nyata (probabilitas) $=5 \%=0,05$ dan dari hasil Regresi SEM diperoleh probabilitas $\mathrm{t}_{\text {-hitung }}=$ 0,006. Berdasarkan hasil olah data diperoleh nilai probabilitas $t_{\text {-hitung }}(0,006)<$ Level of Significant $(0,05)$, maka disimpulkan bahwa variabel manfaat operasional ERP $\left(\mathrm{X}_{1}\right)$ berpengaruh signifikan terhadap Kinerja $S C M$ di proses bisnis eksternal PT. Latinusa Tbk $\left(\mathrm{Y}_{2}\right)$. Hal ini dapat diartikan, jika manfaat operasional ERP meningkat dalam arti bahwa, jika responden menurut responden implementasi ERP dapat mengurangi waktu siklus, implementasi $E R P$ dapat meningkatkan manajemen 
kualitas dan kontrol, dan implementasi ERP dapat memenuhi kebutuhan pelanggan secara proaktif dan lebih efisien, maka Kinerja SCM di proses bisnis eksternal PT. Latinusa Tbk akan mengalami peningkatan.

Hasil analisis Structural Equation Model (SEM) menunjukkan bahwa Pengujian pengaruh variabel manfaat operasional ERP $\left(\mathrm{X}_{1}\right)$ terhadap variabel kinerja $S C M$ pada layanan pelanggan PT. Latinusa Tbk $\left(\mathrm{Y}_{3}\right)$. Dengan taraf nyata (probabilitas) $=5 \%=0,05$ dan dari hasil Regresi SEM diperoleh probabilitas $\mathrm{t}_{\text {-hitung }}=$ 0,013. Berdasarkan hasil olah data diperoleh nilai probabilitas $t_{\text {-hitung }}(0,013)<$ Level of Significant $(0,05)$, maka disimpulkan bahwa variabel manfaat operasional $\operatorname{ERP}\left(\mathrm{X}_{1}\right)$ berpengaruh signifikan terhadap kinerja $S C M$ pada layanan pelanggan PT. Latinusa Tbk $\left(\mathrm{Y}_{3}\right)$. Hal ini dapat diartikan, jika manfaat operasional ERP meningkat dalam arti bahwa, jika menurut responden implementasi ERP dapat mengurangi waktu siklus, implementasi ERP dapat meningkatkan manajemen kualitas dan kontrol, dan implementasi ERP dapat memenuhi kebutuhan pelanggan secara proaktif dan lebih efisien, maka kinerja $S C M$ pada layanan pelanggan PT. Latinusa Tbk akan mengalami peningkatan.

Hasil analisis Structural Equation Model (SEM) menunjukkan bahwa Pengujian pengaruh variabel manfaat operasional ERP $\left(\mathrm{X}_{1}\right)$ terhadap variabel kinerja $S C M$ dalam manajemen biaya PT. Latinusa Tbk $\left(\mathrm{Y}_{4}\right)$. Dengan taraf nyata (probabilitas) $=5 \%=0,05$ dan dari hasil Regresi SEM diperoleh probabilitas $\mathrm{t}_{\text {-hitung }}=$ 0,038 . Berdasarkan hasil olah data diperoleh nilai probabilitas $t_{\text {-hitung }}(0,038)<$ Level of Significant $(0,05)$, maka disimpulkan bahwa variabel manfaat operasional ERP $\left(\mathrm{X}_{1}\right)$ berpengaruh signifikan terhadap kinerja $S C M$ dalam manajemen biaya PT. Latinusa Tbk $\left(\mathrm{Y}_{4}\right)$. Hal ini dapat diartikan, jika manfaat operasional ERP meningkat dalam arti bahwa, jika menurut responden implementasi ERP dapat mengurangi waktu siklus, implementasi ERP dapat meningkatkan manajemen kualitas dan kontrol, dan implementasi ERP dapat memenuhi kebutuhan pelanggan secara proaktif dan lebih efisien, maka kinerja $S C M$ dalam manajemen biaya PT. Latinusa Tbk akan mengalami peningkatan

Hasil analisis Structural Equation Model (SEM) menunjukkan bahwa Pengujian pengaruh variabel manfaat taktis ERP $\left(\mathrm{X}_{2}\right)$ terhadap variabel Kinerja $S C M$ di proses bisnis internal PT. Latinusa Tbk $\left(\mathrm{Y}_{1}\right)$. Dengan taraf nyata (probabilitas) $=5 \%=$ 0,05 dan dari hasil Regresi SEM diperoleh probabilitas $\mathrm{t}_{\text {-hitung }}=0,000$. Berdasarkan hasil olah data diperoleh nilai probabilitas $\mathrm{t}$. hitung $(0,000)<$ Level of Significant $(0,05)$, maka disimpulkan bahwa variabel manfaat taktis ERP $\left(\mathrm{X}_{2}\right)$ berpengaruh signifikan terhadap Kinerja $S C M$ di proses bisnis internal PT. Latinusa Tbk $\left(\mathrm{Y}_{1}\right)$. Hal ini dapat diartikan, jika manfaat taktis ERP meningkat dalam arti bahwa, jika menurut implementasi ERP dapat meningkatkan pengelolaan sumber daya manajemen yang baik, implementasi ERP pengambilan keputusan menjadi lebih efektif bagi para pekerja, implementasi ERP dapat meningkatkan perbaikan kinerja, implementasi ERP terjadi hubungan dengan pelanggan dan penjual (manajemen dalam dan diluar perusahaan), dan implementasi $E R P$ dapat meningkatkan manajemen kualitas dan kualitas kontrol, maka Kinerja $S C M$ di proses bisnis internal PT. Latinusa Tbk akan mengalami peningkatan.

Hasil analisis Structural Equation Model (SEM) menunjukkan bahwa Pengujian pengaruh variabel manfaat taktis ERP $\left(\mathrm{X}_{2}\right)$ terhadap variabel Kinerja $S C M$ di proses bisnis eksternal PT. Latinusa Tbk $\left(\mathrm{Y}_{2}\right)$. Dengan taraf nyata (probabilitas) $=5 \%$ $=0,05$ dan dari hasil Regresi SEM diperoleh probabilitas $t_{\text {-hitung }}=0,045$. Berdasarkan 
hasil olah data diperoleh nilai probabilitas $\mathrm{t}$ hitung $(0,045)<$ Level of Significant $(0,05)$, maka disimpulkan bahwa variabel manfaat taktis ERP $\left(\mathrm{X}_{2}\right)$ berpengaruh signifikan terhadap Kinerja $S C M$ di proses bisnis eksternal PT. Latinusa Tbk $\left(\mathrm{Y}_{2}\right)$. Hal ini dapat diartikan, jika manfaat taktis ERP meningkat dalam arti bahwa, jika menurut implementasi ERP dapat meningkatkan pengelolaan sumber daya manajemen yang baik, implementasi ERP pengambilan keputusan menjadi lebih efektif bagi para pekerja, implementasi ERP dapat meningkatkan perbaikan kinerja, implementasi ERP terjadi hubungan dengan pelanggan dan penjual (manajemen dalam dan diluar perusahaan), dan implementasi $E R P$ dapat meningkatkan manajemen kualitas dan kualitas kontrol, maka Kinerja $S C M$ di proses bisnis eksternal PT. Latinusa Tbk akan mengalami peningkatan.

Hasil analisis Structural Equation Model (SEM) menunjukkan bahwa Pengujian pengaruh variabel manfaat taktis ERP $\left(\mathrm{X}_{2}\right)$ terhadap variabel kinerja $S C M$ pada layanan pelanggan PT. Latinusa Tbk $\left(\mathrm{Y}_{3}\right)$. Dengan taraf nyata (probabilitas) $=5 \%$ $=0,05$ dan dari hasil Regresi SEM diperoleh probabilitas $t_{\text {-hitung }}=0,007$. Berdasarkan hasil olah data diperoleh nilai probabilitas $\mathrm{t}$. hitung $(0,007)<$ Level of Significant $(0,05)$, maka disimpulkan bahwa variabel manfaat taktis ERP $\left(\mathrm{X}_{2}\right)$ berpengaruh signifikan terhadap kinerja $S C M$ pada layanan pelanggan PT. Latinusa Tbk $\left(\mathrm{Y}_{3}\right)$. Hal ini dapat diartikan, jika manfaat taktis ERP meningkat dalam arti bahwa, jika menurut implementasi ERP dapat meningkatkan pengelolaan sumber daya manajemen yang baik, implementasi ERP pengambilan keputusan menjadi lebih efektif bagi para pekerja, implementasi ERP dapat meningkatkan perbaikan kinerja, implementasi ERP terjadi hubungan dengan pelanggan dan penjual (manajemen dalam dan diluar perusahaan), dan implementasi
$E R P$ dapat meningkatkan manajemen kualitas dan kualitas kontrol, maka kinerja $S C M$ pada layanan pelanggan PT. Latinusa Tbk akan mengalami peningkatan.

Hasil analisis Structural Equation Model (SEM) menunjukkan bahwa Pengujian pengaruh variabel manfaat taktis ERP $\left(\mathrm{X}_{2}\right)$ terhadap variabel kinerja $S C M$ dalam manajemen biaya PT. Latinusa Tbk $\left(\mathrm{Y}_{4}\right)$. Dengan taraf nyata (probabilitas) $=5 \%$ $=0,05$ dan dari hasil Regresi SEM diperoleh probabilitas $\mathrm{t}_{\text {-hitung }}=0,024$. Berdasarkan hasil olah data diperoleh nilai probabilitas t. hitung $(0,024)<$ Level of Significant $(0,05)$, maka disimpulkan bahwa variabel manfaat taktis ERP $\left(\mathrm{X}_{2}\right)$ berpengaruh signifikan terhadap kinerja $S C M$ dalam manajemen biaya PT. Latinusa Tbk $\left(\mathrm{Y}_{4}\right)$. Hal ini dapat diartikan, jika manfaat taktis ERP meningkat dalam arti bahwa, jika menurut implementasi ERP dapat meningkatkan pengelolaan sumber daya manajemen yang baik, implementasi ERP pengambilan keputusan menjadi lebih efektif bagi para pekerja, implementasi ERP dapat meningkatkan perbaikan kinerja, implementasi ERP terjadi hubungan dengan pelanggan dan penjual (manajemen dalam dan diluar perusahaan), dan implementasi ERP dapat meningkatkan manajemen kualitas dan kualitas kontrol, maka kinerja $S C M$ pada layanan pelanggan PT. Latinusa Tbk akan mengalami peningkatan.

Hasil analisis Structural Equation Model (SEM) menunjukkan bahwa Pengujian pengaruh variabel manfaat strategis ERP $\left(\mathrm{X}_{3}\right)$ terhadap variabel Kinerja $S C M$ di proses bisnis internal PT. Latinusa Tbk $\left(\mathrm{Y}_{1}\right)$. Dengan taraf nyata (probabilitas) $=5 \%=0,05$ dan dari hasil Regresi SEM diperoleh probabilitas $t_{\text {-hitung }}=0,007$. Berdasarkan hasil olah data diperoleh nilai probabilitas $\mathrm{t}_{\text {-hitung }}(0,007)<$ Level of Significant $(0,05)$, maka disimpulkan bahwa variabel manfaat strategis $\operatorname{ERP}\left(\mathrm{X}_{3}\right)$ berpengaruh signifikan terhadap Kinerja 
SCM di proses bisnis internal PT. Latinusa Tbk $\left(\mathrm{Y}_{1}\right)$. Hal ini dapat diartikan, jika manfaat taktis ERP meningkat dalam arti bahwa, jika menurut implementasi ERP dapat meningkatkan pengelolaan sumber daya manajemen yang baik, implementasi $E R P$ pengambilan keputusan menjadi lebih efektif bagi para pekerja, implementasi ERP dapat meningkatkan perbaikan kinerja, implementasi ERP terjadi hubungan dengan pelanggan dan penjual (manajemen dalam dan diluar perusahaan), dan implementasi $E R P$ dapat meningkatkan manajemen kualitas dan kualitas kontrol, maka kinerja $S C M$ dalam manajemen biaya PT. Latinusa Tbk akan mengalami peningkatan.

Hasil analisis Structural Equation Model (SEM) menunjukkan bahwa Pengujian pengaruh variabel manfaat strategis $\operatorname{ERP}\left(\mathrm{X}_{3}\right)$ terhadap variabel Kinerja $S C M$ di proses bisnis eksternal PT. Latinusa Tbk $\left(\mathrm{Y}_{2}\right)$. Dengan taraf nyata (probabilitas) $=5 \%=0,05$ dan dari hasil Regresi SEM diperoleh probabilitas $t_{\text {-hitung }}=0,000$. Berdasarkan hasil olah data diperoleh nilai probabilitas $\mathrm{t}_{\text {-hitung }}(0,000)<$ Level of Significant $(0,05)$, maka disimpulkan bahwa variabel manfaat strategis $\operatorname{ERP}\left(\mathrm{X}_{3}\right)$ berpengaruh signifikan terhadap Kinerja $S C M$ di proses bisnis eksternal PT. Latinusa Tbk $\left(\mathrm{Y}_{2}\right)$. Hal ini dapat diartikan, jika manfaat strategis ERP meningkat dalam arti bahwa, jika menurut responden implementasi ERP dapat membangun inovasi bisnis, implementasi ERP dapat mengurangi biaya persediaan, implementasi $E R P$ dapat membangun hubungan eksternal agar lebih baik dengan pelanggan dan pemasok, dan implementasi ERP menhasilkan produk yang berbeda seperti customization, maka Kinerja SCM di proses bisnis internal PT. Latinusa Tbk akan mengalami peningkatan.

Hasil analisis Structural Equation Model (SEM) menunjukkan bahwa Pengujian pengaruh variabel manfaat strategis $E R P\left(\mathrm{X}_{3}\right)$ terhadap variabel kinerja $S C M$ pada layanan pelanggan PT. Latinusa Tbk $\left(\mathrm{Y}_{3}\right)$. Dengan taraf nyata (probabilitas) $=5 \%=0,05$ dan dari hasil Regresi SEM diperoleh probabilitas $t_{\text {-hitung }}=0,004$. Berdasarkan hasil olah data diperoleh nilai probabilitas $\mathrm{t}_{\text {-hitung }}(0,004)<$ Level of Significant $(0,05)$, maka disimpulkan bahwa variabel manfaat strategis $\operatorname{ERP}\left(\mathrm{X}_{3}\right)$ berpengaruh signifikan terhadap kinerja $S C M$ pada layanan pelanggan PT. Latinusa Tbk $\left(\mathrm{Y}_{3}\right)$. Hal ini dapat diartikan, jika manfaat strategis ERP meningkat dalam arti bahwa, jika menurut responden implementasi ERP dapat membangun inovasi bisnis, implementasi ERP dapat mengurangi biaya persediaan, implementasi ERP dapat membangun hubungan eksternal agar lebih baik dengan pelanggan dan pemasok, dan implementasi ERP menhasilkan produk yang berbeda seperti customization, maka Kinerja SCM di proses bisnis eksternal PT. Latinusa Tbk akan mengalami peningkatan.

\section{Hasil analisis Structural Equation} Model (SEM) menunjukkan bahwa Pengujian pengaruh variabel manfaat strategis $\operatorname{ERP}\left(\mathrm{X}_{3}\right)$ terhadap variabel kinerja $S C M$ dalam manajemen biaya PT. Latinusa Tbk $\left(\mathrm{Y}_{4}\right)$. Dengan taraf nyata (probabilitas) $=5 \%=0,05$ dan dari hasil Regresi SEM diperoleh probabilitas $\mathrm{t}_{\text {-hitung }}=0,000$. Berdasarkan hasil olah data diperoleh nilai probabilitas $\mathrm{t}_{\text {-hitung }}(0,000)<$ Level of Significant $(0,05)$, maka disimpulkan bahwa variabel manfaat strategis ERP $\left(\mathrm{X}_{3}\right)$ berpengaruh signifikan terhadap kinerja $S C M$ dalam manajemen biaya PT. Latinusa Tbk $\left(\mathrm{Y}_{4}\right)$. Hal ini dapat diartikan, jika manfaat strategis ERP meningkat dalam arti bahwa, jika rmenurut responden implementasi ERP dapat membangun inovasi bisnis, implementasi ERP dapat mengurangi biaya persediaan, implementasi $E R P$ dapat membangun hubungan eksternal agar lebih baik dengan pelanggan dan 
pemasok, dan penerapan ERP menghasilkan produk yang berbeda seperti customization, maka kinerja $S C M$ pada layanan pelanggan PT. Latinusa Tbk akan mengalami peningkatan.

\section{SIMPULAN}

Dilihat dari hasil pembahasan, maka dapat disimpulkan bahwasanya implementasi ERP (Enterprise Resource Planning) yang terdiri dari manfaat operasional ERP, manfaat taktis ERP, dan manfaat strategis ERP berpengaruh signifikan terhadap kinerja SCM (Supply Chain Management) yang terdiri dari kinerja $S C M$ di proses bisnis internal, kinerja SCM di proses bisnis eksternal, kinerja $S C M$ pada layanan pelanggan, dan kinerja $S C M$ dalam manajemen biaya PT. Latinusa Tbk. Hal ini dapat diartikan, jika penerapan ERP (Enterprise Resource Planning) yang terdiri dari manfaat operasional $E R P$, manfaat taktis $E R P$, dan manfaat strategis ERP mengalami peningkatan, maka kinerja SCM (Supply Chain Management) yang terdiri dari kinerja $S C M$ di proses bisnis internal, kinerja SCM di proses bisnis eksternal, kinerja $S C M$ pada layanan pelanggan, dan kinerja $S C M$ dalam manajemen biaya PT. Latinusa Tbk juga akan mengalami peningkatan. Berkaitan dengan signifikannya pengaruh penerapan ERP (Enterprise Resource Planning) terhadap kinerja SCM (Supply Chain Management), maka dapat diberikan saran untuk lebih meningkatkan penerapan ERP (Enterprise Resource Planning) dengan cara PT. Latinusa Tbk lebih mengimplementasikan dalam mengurangi waktu siklus, lebih meningkatkan manajemen kualitas dan kontrol, memenuhi kebutuhan pelanggan secara proaktif dan lebih efisien, lebih meningkatkan pengelolaan sumber daya manajemen yang baik, lebih meningkatkan perbaikan kinerja, lebih meningkatkan manajemen kualitas dan kualitas kontrol, membangun inovasi bisnis, implementasi $E R P$, dan lebih membangun hubungan eksternal agar lebih baik dengan pelanggan dan pemasok. Dengan demikian, maka kinerja SCM (Supply Chain Management) akan meningkat lebih baik.

\section{REFERENSI}

Abu-Shanab, E., Abu-Shehab, R., \& Khairallah, M. (2015). Critical success factors for ERP implementation: The case of Jordan. The International Arab Journal of e-Technology, 4(1), 1-7.

Akkermans, H.A., Bogerd, P., Yucesan, E., \& van Wassenhove, L.N. (2003). The impact of ERP on supply chain management: Exploratory findings from a European Delphi study. European Journal of Operational Research, 146 (2), 284301.

Banwait, K., \& Laroiya, S. (2010). Performance evaluation of ERP Implementation in Indian SMEs. Journal of Manufacturing Technology, 21(6), 759-780.

Bowersox, D.J.; Closs, D.J.; Cooper, B.M. (2002). Supply Chain Logistics Management [Electronic version], McGrawHill: New York.

Bowersox, D. J., D. J. Closs and T. P., Stank. (1999). 21st century logistics: making supply chain integration a reality. Oak Brook, IL: Council of Logistics Management.

Forslund, H. (2010). ERP Systems' Capabilities for Supply Chain Performance Management. Industrial Management dan Data Systems, 110(3), 351-367.

Gunasekaran, angapa, et al. (2009). A Framework For Supply Chain Performance Measurment. International Journal Of Production Economics, 87(3). 
Kurniawati, Elisabeth Penti \& Permadi, F.X Rahardian Eka. (2011). Penerapan Enterprise Resource Planning System pada PT Garuda Indonesia (Persero). Jurnal Manajemen dan Keuangan, 9(2), 88-108.

Holmes-Smith, P. (2001) Introduction to Structural Equation Modelling Using LISREL. ACSPRI-Winter Training Program, Perth.

Saini, S., Nigam, S., \& Misra, S. C. (2013). Identifying success factors for implementation of ERP at Indian SMEs. Journal of Modelling in Management, $\quad 8(1), \quad$ 103-122. https://doi.org/10.1108/1746566131131 2003

Shang, S and Seddon, P.B. (2000). A comprehensive framework for classiying the benefits of ERP Systems. Americas Conference on Information Systems, 1005- 1014

Tarigan, Josua. (2013). Enterprise Resource Planning (ERP) : Dampak dalam Pendidikan, profesi Akuntan dan Auditor. Universitas Kristen Petra Tarhini, A., Ammar, H., Tarhini, T., \& Masa'deh, R. (2015). Analysis of the Critical Success Factors for Enterprise Resource Planning Implementation from Stakeholders' perspective: A Systematic Review. International Business Research, 8(4), 25-40

Wicaksono et, al. (2015). Analisis Dampak Penerapan Sistem ERP terhadap Kinerja Pengguna.Binus Business Review, 6(1), 25-34. 